\title{
Analisis Preferensi dan Kepuasan Penerima Bantuan Pangan Non Tunai (BPNT) terhadap Beras di Kota Denpasar
}

\author{
DEWA AYU INDAH YULANDARI, I WAYAN BUDIASA, \\ I DEWA GEDE RAKA SARJANA.
}

Program Studi Agribisnis Fakultas Pertanian Universitas Udayana

J1. PB. Sudirman Denpasar 80232

Email: indahyulandari@yahoo.com

Wba.agr@unud.ac.id

\section{Abstract \\ Analysis of Preference and Satisfaction of Non-Cash Food Aid Recipients (BPNT) Against Rice in Denpasar City.}

Income differences are one indicator of differences in social classes. The role of government is very influential in the lower middle class. The government assistance program in the form of Rastra, is channeled in non-cash by transforming from assistance to subsidy patterns to social assistance (food). The purpose of this study to determine the characteristics, preferences and customer satisfaction of rice recipients of Non-Cash Food Aid (BPNT) was assessed from the level of importance and level of performance of the attributes of rice provided by rice suppliers in Denpasar City. Data collection method with survey technique and indepth interview. Data analysis used is descriptive analysis, Customer Satisfaction Index and Importance Performance Analysis. Based on this study the characteristics of the dominating respondents, namely the owner of an electronic account are women as the couple's head of the family. The high and low education does not affect the income they have. Most respondents are from the lower class who are registered as KPM and are entitled to rice assistance from the BPNT program. Rice endurance is the highest value attribute that is an assessment of consumer preferences. The satisfaction index of rice BPNT recipients with a total of $80.46 \%$ is in the range of $81 \%-100 \%$ in the category of very satisfied with some improvements from the results of the IPA method. The results of the Cartesius diagram attribute of rice resistance are the main priority to be improved because it is in quadrant I.

Keywords: rice, preferences, and customer satisfaction

\section{Pendahuluan}

\subsection{Latar Belakang}

Konsumen beras terdapat beragam kelas sosial, dilihat dari pekerjaan, pendapatan, kekayaan, dan kelas sosial. Perbedaan pendapatan merupakan salah satu indikator perbedaan kelas sosial. Faktor ini menyebabkan perbedaan perilaku konsumen dalam mengkonsumsi beras pada kelas sosial yang berbeda (Selamet, 2003).

Peran pemerintah sangat berpengaruh besar pada kelompok kelas menengah ke bawah. Program Penanggulangan Kemiskinan dan Ketimpangan Ekonomi memberikan 
arahan bahwa mulai tahun anggaran 2017 penyaluran manfaat Raskin agar dilakukan melalui kupon elektronik (e-voucher) sehingga dapat tepat sasaran dan lebih mudah dipantau (Kemensos, 2017). Penyaluran bantuan pangan secara non tunai diharapkan dapat berdampak bagi peningkatan kesejahteraan dan kemampuan ekonomi penerima manfaat. Pemerintah selama ini berusaha keras pada peningkatan kuantitas dan produktivitas beras untuk mencukupi kebutuhan dalam negeri. Strategi peningkatan kuantitas, preferensi dan kepuasan yang terus berkembang dan adanya peningkatan pada kualitas beras yang selama ini dikonsumsi oleh penerima BPNT tersebut.

Kota Denpasar merupakan salah satu daerah yang sudah menerapkan program Bantuan Pangan Non Tunai (BPNT). Masyarakat yang terdaftar sebagai Pekerja Keluarga Harapan (PKH) di Dinas Sosial Kota Denpasar. Total realisasi penerima BPNT sejumlah 3114. Penerima BPNT di Kota Denpasar memiliki karakteristik masyrakat yang beraneka ragam dan tentunya memiliki penilaian tentang preferensi mengkonsumsi beras dan kepuasan setelah mengkonsumsi beras yang diberikan oleh penyalur beras melalui program BPNT tersebut. Keragaman meliputi usia, jenis kelamin, pendidikan dan pekerjaan, serta tingkat perekonomian (kelas sosial) yang tercermin dalam kehidupan sehari-hari. Konsumen penerima BPNT di kota Denpasar memiliki keragaman yang tercipta tentu mempengaruhi preferensi dan kepuasan konsumen penerima BPNT terhadap beras yang disediakan oleh pemerintah kota Denpasar.

\subsection{Rumusan Masalah}

Berdasarkan uraian di atas, maka permasalahan yang akan dikaji pada penelitian ini adalah.

1. Bagaimana karakteristik sosial ekonomi penerima BPNT di Kota Denpasar?

2 Bagaimana preferensi penerima BPNT di Kota Denpasar dikaitkan dengan atributatribut beras yang disediakan oleh penyalur beras?

3 Bagaimana tingkat kepuasan penerima BPNT di Kota Denpasar dikaitkan dengan atribut-atribut beras yang disediakan oleh penyalur beras?

\subsection{Tujuan Penelitian}

Tujuan penelitian ini adalah sebagai berikut.

1. Mengkaji karakteristik sosial ekonomi penerima beras BPNT di kota Denpasar

2. Menganalisis preferensi penerima beras BPNT di kota Denpasar dikaitkan dengan atribut-atribut beras yang disediakan oleh penyalur beras.

3. Menganalisis tingkat kepuasan penerima beras BPNT di kota Denpasar dikaitkan dengan atribut-atribut beras yang disediakan oleh penyalur beras.

\section{Metode Penelitian}

\subsection{Lokasi dan Waktu Penelitian}

Penelitian ini dilaksanakan di empat Kecamatan di Kota Denpasar Penelitian dilakukan pada bulan Maret sampai Juni 2018. Pemilihan lokasi penelitian secara purposive yaitu Dinas Sosial Kota Denpasar sudah menetapkan warung atau toko sembako di setiap kecamatan yang menjadi E-Warong tempat penyalur beras untuk program BPNT. 


\subsection{Sampel Penelitian, Jenis Data, dan Analisis Data}

Sampel adalah sebagian atau wakil dari populasi yang diambil menjadi sumber data yang sebenarnya dengan menggunakan cara-cara tertentu (Margono, 2004). Metode penarikan sampel yang digunakan dalam penelitian ini adalah Non Proportional Random Sampling yaitu suatu cara pengambilan sampel secara acak tanpa memperhatikan besar kecilnya perimbangan yang terdapat pada strata dalam populasi (Sugiyono, 1999). Jumlah sampel dalam penelitian ini yaitu 120, terdapat 30 sampel di empat kecamatan yang ada di Kota Denpasar yaitu Denpasar Utara, Denpasar Timur, Denpasar Barat dan Denpasar Selatan.

Jenis data penelitian ini adalah kuantitatif dan kualitatitf. Data Kuantitatif data yang dapat dihitung dan dalam bentuk angka-angka (Ulfiahrami, 2011). Data kuantitatif yang dicari dalam penelitian ini adalah data yang akan diisi oleh responden penerima BPNT melalui kuisioner, umur, pendidikan, pendapatan responden penerima BPNT di kota Denpasar (Rp/bulan), dan data jumlah realisasi BPNT yang didapatkan di Dinas Sosial Kota Denpasar. Data kualitatif, data informasi yang berbentuk kalimat verbal (Sugiyono, 2008). dalam penelitian ini berdasarkan keterangan yang berhubungan dengan gambaran umum BPNT, lokasi penelitian, identitas responden serta data lainnya yang menunjang penelitian.

Analisis data yang dilakukan pada penelitian ini digunakan metode penelitian dengan sebagai berikut.

1. Uji validitas

Validitas adalah suatu ukuran yang menunjukkan tingkat validitas atau kesahihan suatu instrument (Simamora 2004). Suatu instrument dianggap valid apabila mampu mengukur apa yang diinginkan. Uji validitas digunakan untuk menghitung nilai korelasi (r) antara data pada masing-masing pertanyaan dengan skor total.

$$
r_{\text {hitung }}-\frac{n(\Sigma X Y)-(\Sigma X)(\Sigma Y)}{\sqrt{\left(n\left(\Sigma X^{2}\right)-(\Sigma X)^{2}\right]\left[n\left(\Sigma Y^{2}\right)-(\Sigma Y)^{2}\right]}}
$$

Dimana:

$\mathrm{r}=$ koefisien korelasi

$\mathrm{Y}=$ nilai total skor

$\mathrm{X}=$ skor indikator empiris penelitian

$\mathrm{N}=$ jumlah sampel

Apabila diperoleh $\mathrm{r}$ hitung lebih besar daripada $\mathrm{r}$ tabel pada tingkat signifikan ( $\alpha$ ) 0,05 maka pernyataan pada kuesioner mempunyai validitas konstruk atau terdapat konsistensi internal dalam pernyataan tersebut dan layak digunakan.

\section{Uji Reliabilitas}

Reliabilitas adalah suatu nilai yang menunjukkan konsistensi suatu alat pengukuran gejala yang sama (Umar dalam Achmad, 2012). Untuk menguji reliabilitas dapat menggunakan rumus Cronbach Alpha (Sujarweni dan Endrayanto, 2012:3186), dengan rumus sebagai berikut:

$$
r u=\frac{k \cdot r}{1+(k-1) r}
$$


Dimana:

$\alpha=$ Keandalan alpha cronbach

$\mathrm{r}$ = Rata-rata korelasi diantara butir pertanyaan

$\mathrm{k}=$ Jumlah butir pertanyaan dalam skala

Kriteria pengujian adalah sebagai berikut.

a. Nilai alpha Cronbach jika $(\alpha)>0,60$ maka item variabel dinyatakan reliabel

b. Nilai alpha Cronbach jika $(\alpha)<0,60$ maka item variabel dinyatakan tidak reliabel

\section{Customer Satisfaction Index (CSI)}

Customer Satisfaction Index (CSI) digunakan untuk menentukan tingkat kepuasan pelanggan secara menyeluruh dengan pendekatan yang mempertimbangkan tingkat kepentingan dari atribut-atribut kualitas jasa yang diukur. Metode pengukuran CSI meliputi tahap-tahap sebagai berikut (Stratford dalam Suherman, 2007) :

(1) Menghitung weighting factors $(W F)$, yaitu mengubah nilai tingkat kepentingan masing-masing atribut menjadi angka persentase (\%) dari total nilai rata-rata tingkat kepentingan untuk seluruh atribut yang diuji.

(2) Menghitung weigted score (WS), yaitu nilai perkalian antar nilai rata-rata tingkat kinerja atau kepuasan atau mean satisfaction score (MSS) masing-masing atribut dengan weighting factors masing-masing atribut.

(3) Menghitung weighted total (WT), yaitu menjumlahkan weigted score dari semua atribut.

(4) Menghitung customer satisfaction index (CSI), yaitu weight total (WT) dibagi highest scale (HS) atau skala maksimal yang digunakan (penelitian ini menggunakan skala maksimal 5). Berdasarkan rentang skala di atas, maka kriteria kepuasannya adalah sebagai berikut.

$$
\mathrm{CSI}=\frac{\mathrm{wS}}{H S} \times 100 \%
$$

Tabel 1.

Rentang Skala dan Interpretasi Analisis Customer Satisfaction Index (CSI)

\begin{tabular}{cc}
\hline Angka Indeks & Interpretasi \\
\hline $0 \%-20 \%$ & Tidak Puas \\
$21 \%-40 \%$ & Kurang Puas \\
$41 \%-60 \%$ & Cukup Puas \\
$61 \%-80 \%$ & Puas \\
$81 \%-100 \%$ & Sangat Puas \\
\hline
\end{tabular}

Sumber: Patiroi (2008)

4. Importance Performance Analysis (IPA)

Importance and Performance Analysis (IPA) yaitu analisis tingkat kepentigan dan kinerja. Tingkat kepentingan yang dimaksud adalah seberapa penting suatu atribut bagi pelanggan. Tingkat kinerja adalah kinerja actual dari atribut yang dirasakan oleh 
konsumen. Importance Performance analysis menghasilkan empat kuadran dibatasi oleh dua buah garis yang berpotongan tegak lurus pada titik-titik ( X, Y ) (Rangkuti, 2003).

\section{Hasil dan Pembahasan}

\subsection{Karakteristik Sosial Ekonomi Penerima BPNT}

Hasil penelitian responden dalam penelitian ini terdapat $100 \%$ perempuan sebagai IRT dengan status sudah menikah karena akun eletronic BPNT atas nama pasangan dari kepala keluarga. Responden didominasi oleh konsumen dengan usia berkisar 36-45 tahun sebanyak $50 \%$. Responden dengan agama dan asal lebih banyak beragama hindu merupakan penduduk asli Bali dengan jumlah 52\%. Rata-rata pendidikan terakhir responden yaitu SD sebanyak $57 \%$ dengan pendapatan yang tidak tentu berkisar Rp. $\leq$ 800.000 sebanyak $71 \%$ merupakan kelas bawah atau keluarga sejahtera tahap I.

\subsection{Preferensi Tingkat Kepentingan dan Tingkat Kinerja}

Preferensi konsumen didapatkan dengan mengukur perbandingan nilai rata-rata tingkat penilaian kepentingan yang terdapat pada atribut beras. Atribut dengan nilai tertinggi merupakan atribut yang berpengaruh dalam memilih beras yang akan diterima dan dikonsumsi oleh penerima BPNT. Tabel 2 atribut kepulenan beras medapatkan skor diatas rata-rata tingkat kepentingan tertinggi menurut responden. Atribut dengan tingkat kepentingan dibawah rata-rata yaitu atribut iklan beras yang dianggap tidak terlalu diperhatikan oleh responden.

Penilaian tingkat kinerja, responden memberikan penilaian dengan skala likert mulai dari skor 1 sangat tidak puas sampai 5 sangat puas tujuannya untuk menilai tingkat kinerja atribut beras yang diterima oleh konsumen penerima BPNT. Tabel 2 responden menilai kinerja yang kurang baik pada atribut kemasan beras dan warna beras yang memiliki total skor terendah dibawah rata-rata oleh konsumen penerima BPNT. Atribut dengan skor kepuasan diatas rata-rata tertinggi terdapat pada atribut kebersihan beras yang disediakan oleh penyalur beras. Harga beras yang sesuai dengan jumlah bantuan non tunai yang di dapatkan, responden menilai bahwa beras yang didapatkan mempunyai kualitas yang baik tidak jauh beda dengan kualitas beras dengan merek terkenal pada umumnya. 
Tabel 2.

Jumlah dan Rata-rata Tingkat Kepentingan dan Tingkat Kinerja Atribut Beras

\begin{tabular}{clcccc}
\hline \multirow{2}{*}{ No } & \multirow{2}{*}{ Atribut } & \multicolumn{2}{c}{ Tingkat Kepentingan } & \multicolumn{2}{c}{ Tingkat Kinerja } \\
\cline { 3 - 6 } & & Total & Rata-rata & Total & Rata-rata \\
\hline 1 & Kepulenan beras & 578 & 4,82 & 502 & 4,18 \\
2 & Aroma nasi & 537 & 4,48 & 465 & 3,88 \\
3 & Warna beras & 522 & 4,35 & 434 & 3,62 \\
4 & Kebersihan beras & 565 & 4,71 & 516 & 4,3 \\
5 & Daya tahan beras & 574 & 4,78 & 458 & 3,82 \\
6 & Kemasan beras & 448 & 3,73 & 422 & 3,52 \\
7 & Lokasi penjualan beras & 548 & 4,57 & 486 & 4,05 \\
8 & Kenyamanan tempat pembelian beras & 539 & 4,49 & 499 & 4,16 \\
9 & Informasi oleh pedagang & 557 & 4,64 & 506 & 4,22 \\
10 & Pelayanan di tempat pembelian & 553 & 4,61 & 512 & 4,27 \\
11 & Kemudahan memperoleh beras & $\mathbf{5 4 9}$ & 4,58 & 494 & 4,12 \\
\hline \multicolumn{2}{c}{ Total } & $\mathbf{5 9 7 0}$ & $\mathbf{4 5 , 1 8}$ & $\mathbf{5 2 9 4}$ & $\mathbf{4 4 , 1 4}$ \\
\hline \multicolumn{2}{c}{ Rata-rata } & $\mathbf{5 4 2 , 7}$ & $\mathbf{4 , 5 2}$ & $\mathbf{4 8 0}$ & $\mathbf{4 , 0 1}$ \\
\hline
\end{tabular}

Sumber: Data Primer (diolah Ms. Excel) 2018

\subsection{Tingkat Kepuasan Konsumen (Customer Satisfaction Index)}

Perhitungan Customer Satisfaction Index (CSI) pada tabel 3 untuk mengetahui tingkat kepuasan yang dihasilkan suatu atribut. Perhitungan dengan menggunakan metode Customer Satisfaction Index (CSI) memerlukan skor rata-rata kepentingan dan rata-rata kinerja atribut yang dihasilkan produk beras pada setiap penyalur beras di masing-masing Kecamatan di Kota Denpasar. Rumus yang digunakan untuk memperoleh hasil perhitungan CSI yaitu total weight score dibagi skala maksimum yaitu 5 dikalikan $100 \%$. Pada penelitian ini nilai perhitungan CSI yaitu 4,023/5= $0,8046 \times 100 \%=80,46 \%$.

Indeks kepuasan konsumen penerima Bantuan Pangan Non Tunai (BPNT) terhadap beras dengan total $80,46 \%$ berada pada rentang $81 \%-100 \%$ sehingga indeks kepuasan konsumen terhadap atribut produk masuk pada kategori sangat puas. Nilai Customer Satisfaction Index (CSI) pada BPNT beras di Kota Denpasar terdapat 19,54\% KPM yang belum terpenuhi harapannya atau belum puas terhadap kinerja atribut produk beras yang didapatkan dari program BPNT yaitu aroma nasi, warna beras, daya tahan beras, kemasan beras, dan kenyamanan tempat pembelian beras. 
Tabel 3.

Perhitungan Customer Satisfaction Index (CSI) Pada Atribut Beras Penerima BPNT di Kota Denpasar

\begin{tabular}{rlrrrc}
\hline NO & \multicolumn{1}{c}{ ATRIBUT } & RSP & WF & RSK & WS \\
\hline & & & & & \\
2 & Kepulenan beras & 4,82 & $9,7 \%$ & 4,18 & 0,405 \\
3 & Wroma nasi & 4,48 & $9,1 \%$ & 3,88 & 0,351 \\
4 & Kebersihan beras & 4,35 & $8,8 \%$ & 3,62 & 0,318 \\
5 & Daya tahan beras & 4,71 & $9,5 \%$ & 4,30 & 0,409 \\
6 & Kemasan beras & 4,48 & $9,1 \%$ & 3,82 & 0,346 \\
7 & Lokasi penjualan beras & 3,73 & $7,5 \%$ & 3,52 & 0,265 \\
8 & Kenyamanan tempat pembelian beras & 4,57 & $9,2 \%$ & 4,05 & 0,374 \\
9 & Informasi oleh pedagang & 4,49 & $9,1 \%$ & 4,16 & 0,378 \\
10 & Pelayanan di tempat pembelian & 4,64 & $9,4 \%$ & 4,22 & 0,396 \\
11 & Kemudahan memperoleh beras & 4,61 & $9,3 \%$ & 4,27 & 0,398 \\
& Rata-rata & 4,58 & $9,3 \%$ & 4,12 & 0,382 \\
\hline & Total & $\mathbf{4 , 5 0}$ & $\mathbf{9 , 1 \%}$ & $\mathbf{4 , 0 1}$ & $\mathbf{0 , 3 6 6}$ \\
\hline & $\quad \mathbf{4 9 , 4 6}$ & $\mathbf{1 , 0 \%}$ & $\mathbf{4 4 , 1 4}$ & $\mathbf{4 , 0 2 3}$ \\
\hline
\end{tabular}

Sumber: Data Primer (diolah Ms. Excel) 2018

Keterangan :

RSP : Rata-rata skor kepentingan

WF :Weighting Factor [WF=(RSPi/49,46 x 100\%)]

RSK : Rata-rata skor kinerja

WS : Weighted Score [WS=(RSK x WF $)]$

\subsection{Importance Performance Analysis (IPA)}

Penelitian ini terdapat 11 atribut beras BPNT yang di dapatkan oleh penerima BPNT dengan jumlah 120 responden. Skor penilaian tingkat kepentingan dan skor penilaian tingkat kinerja pada 11 atribut, sehingga akan memperoleh penilaian tentang seberapa penting atribut-atribut tersebut dengan kinerja kenyataan yang didapatkan. Hasil analisis Importance Performance Analysis (IPA) yaitu berupa atribut yang mempengaruhi strategi peningkatan kepuasan konsumen. Penilaian tingkat kepentingan dan tingkat kinerja dimasukkan ke dalam kuadran yang terbagi menjadi empat dengan bantuan aplikasi analisis data SPSS. 


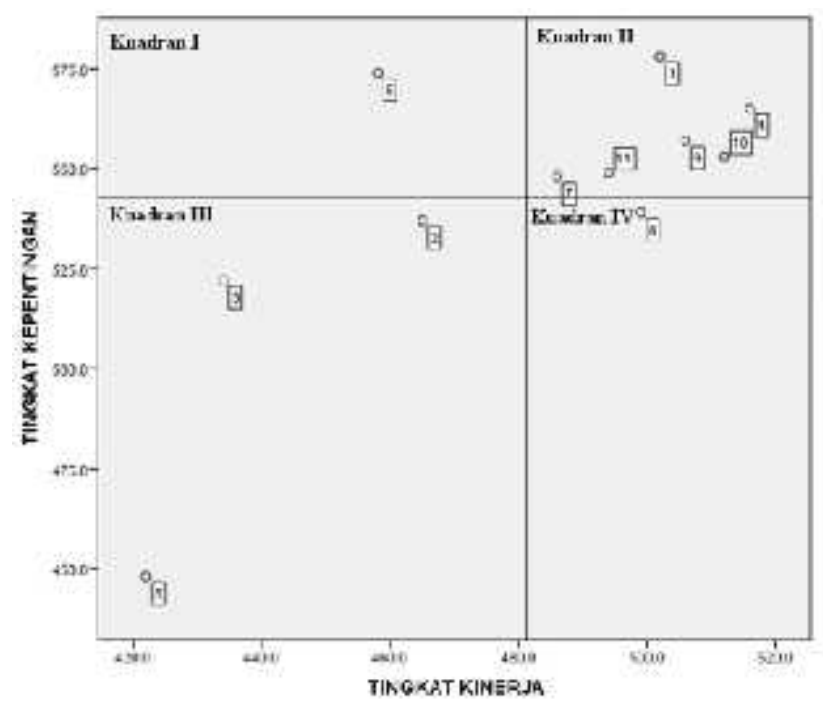

Gambar 1.

Matriks Importance Performance Analysis Program Bantuan Pangan Non Tunai (BPNT) terhadap Beras di Kota Denpasar

\subsubsection{Kuadran I (prioritas utama)}

Kuadran I diagram kartesius Importance Performance Analysis (IPA) merupakan atribut-atribut yang dinilai penting menurut konsumen tetapi memiliki tingkat kinerja yang rendah. Atribut yang berada pada kuadran I adalah daya tahan beras.

\subsubsection{Kuadran II (pertahankan)}

Kuadran II diagram kartesius Importance Performance Analysis (IPA), atributatribut yang berada pada kuadran ini memiliki tingkat kepentingan yang tinggi dan kinerja yang dinilai tinggi sudah memenuhi harapan konsumen. Atribut yang berada pada kuadran II adalah kepulenan beras, kebersihan beras, lokasi penjualan beras, informasi oleh pedagang, pelayanan di tempat pembelian beras, kemudahan memperoleh beras.

\subsubsection{Kuadran III (prioritas rendah)}

Kuadran III diagram kartesius Importance Performance Analysis (IPA) adalah tingkat kepentingan dan tingkat kinerja suatu produk yang dinilai rendah. Atribut yang berada pada kuadran III adalah warna beras, aroma nasi, dan kemasan beras.

\subsubsection{Kuadran IV (berlebihan)}

Kuadran IV diagram kartesius Importance Performance Analysis (IPA) yaitu atribut yang berada pada kuadran ini merupakan atribut yang dinilai tidak terlalu penting oleh konsumen tetapi memiliki kinerja yang dianggap baik oleh konsumen. Atribut kenyamanan tempat pembelian beras berada pada kuadran IV.

\section{Simpulan dan Saran}

\subsection{Simpulan}

1. Preferensi pada penelitian ini yaitu atribut kepulenan beras medapatkan skor dengan tingkat kepentingan tertinggi. 
2. Indeks kepuasan konsumen penerima Bantuan Pangan Non Tunai (BPNT) terhadap beras dengan total $80,46 \%$ berada pada rentang $81 \%$ - $100 \%$ sehingga indeks kepuasan konsumen terhadap atribut produk masuk pada kategori sangat puas. Terdapat $19,54 \%$ atribut dengan nilai dibawah rata-rata.

3. Metode Importance Performance Analysis (IPA) menghasilkan atribut yang menjadi prioritas utama yaitu daya tahan beras. Atribut yang berada pada kuadran I harus menjadi prioritas utama untuk diperbaiki.

\subsection{Saran}

1. Pemerintah perlu memperhatikan kepersertaan dari penerima BPNT tersebut dengan kembali mendata KPM dengan kondisi sosial ekonomi 25\% terendah di daerah pelaksanaan.

2. Atribut yang berada pada kuadran I harus menjadi prioritas utama untuk diperbaiki seperti daya tahan beras. Penyalur beras di masing-masing Kecamatan diharapkan mampu memilih produk beras yang dinilai baik oleh penerima BPNT sehingga penyalur beras dan KPM merasa diuntungkan.

3. Kuadran III merupakan prioritas kedua untuk diperbaiki, terdapat beberapa atribut warna beras, aroma nasi, dan kemasan beras. Pada kuadran III untuk memperbaiki tingkat kinerja tidak akan mempengaruhi kepuasan konsumen keseluruhan namun pihak penyalur beras harus tetap tetap mengutamakan kualitas dari warna, aroma dan kemasan beras yang disediakan dan sesuai dengan jumlah non tunai yang diterima KPM dengan menyediakan brosur tentang informasi produk beras. Pada kuadran IV yaitu kenyamanan tempat pembelian beras dinilai berlebihan kinerjanya, penyalur beras dapat mengefisienkan sumber daya yang ada dengan menyediakan bantuan pangan dan alat elektronik kartu kombo sudah dianggap cukup oleh responden.

\section{Ucapan Terimakasih}

Ucapan terimakasih penulis tujukan kepada Dinas Sosial Kota Denpasar, dan penyalur beras BPNT di Kota Denpasar serta seluruh penerima BPNT di Kota Denpasar yang menjadi responden pada penelitian ini.

\section{Daftar Pustaka}

Dinas Sosial Kota Denpasar. 2017. Data Realisasi BPNT 2017. Dinas Sosial Kota Denpasar.

Kementrian Sosial. 2017. Pedoman pelaksanaan BPNT. Jakarta Pusat.

Margono. 2004. Metode penelitian. http://digilib.unila.ac.id/11058/18/BAB\%20III.pdf. Diakses pada 10 November 2017.

Rangkuti. 2003. Anlisis Importance Performance Analysis (IPA). http://eprints.undip.ac.id/37679/1/KARIMAN.pdf . Diakses tanggal 22 Desember 2017.

Selamet. 2003. Analisis perilaku konsumen. https://repository.ipb.ac.id/jspui/bitstream/123456789/54345/6/pdf. Diakses tanggal 10 November 2017.

Simamora. 2004. Analisis Data Uji Validitas. http://thesis.binus.ac.id/doc/Bab3/2008100208MN\%20BAB\%203.pdf. Diakses tanggal 20 Desember 2017. 
Stratford dalam Suherman. 2008. Analisis Customer Satisfaction Index (CSI). https://repository.ipb.ac.id/jspui/bitstream/123456789/27314/8/Bab\%20III\%2 0Metodologi\%20H10lad\%20(1)-5.pdf. Diakses tanggal 10 Januari 2018.

Sugiyono. $1999 . \quad$ Metode Penarikan Sampel. dalam https://repository.ipb.ac.id/download/pdf. diakses pada 12 Januari 2018.

Sugiyono. 2008. Metode Penelitan Kuantitatif, Kualitatif.. Penerbit Alfabeta: Bandung Ulfiahrami. Analisis

Data

Kuantitatif http://eprints.uny.ac.id/24099/13/BAB\%20III.pdf. Diakses tanggal 20 Desember 2017 